\title{
Changes in pancreatic morphology associated with aging
}

\author{
LOUIS KREEL AND BRENDA SANDIN \\ From the Section of Radiology, Clinical Research Centre, Northwick Park Hospital, Harrow, England
}

SUMMARY Retrograde pancreatography has been carried out at necropsy in 120 cases and the results have been analysed in statistical detail. With increasing age, changes in pancreatic anatomy occur which must not be taken to indicate pathology. These changes are: (1) low or ptotic position of the pancreas so that the papilla of Vater is below the level of L3; (2) calcification of the splenic and superior mesenteric arteries which produce calcific densities around the pancreas; (3) increasing width of main pancreatic duct along its whole length at about $8 \%$ per decade; in the elderly, widths of $1 \mathrm{~cm}$ can occur in the main duct in the head of the pancreas without evidence of obstruction; (4) formation of ductular ectasia which affects mainly the interlobular ductules but also intralobular ductules; (5) some ectatic ducts reach the dimensions of cysts, ie, 1-2 cm in diameter.

Other morphological changes which have been demonstrated and which may produce difficulties in radiological interpretation are: (a) narrowed ducts not due to stricture; $(b)$ space-occupying lesions due to superior mesenteric artery, splenic artery, aorta, vertebral osteophytes, sympathetic ganglion, and lymph nodes; $(c)$ metastases in the pancreas - these must be distinguished from primary pancreatic carcinoma.

The implications of these findings for endoscopy and isotope pancreatic scanning will be mentioned.

In a recent study on pancreatic morphology (Kreel, Sandin, and Slavin, 1973) it was shown that there is a considerable variation in the position and shape of th epancreas as well as in calibre of the duct. Ductular changes were also commonly found. Further work was therefore undertaken to elucidate these problems, and the results have now been subjected to statistical analysis, indicating that some of these variations are related to age. The present communication draws particular attention to the variation in pancreatic morphology related to aging.

\section{Method and Material}

The results of 120 normal necropsy pancreatic duct cannulations, as carried out by the method previously described (Sandin, Kreel, and Slavin, 1973), were

Received for publication 28 September 1973. analysed for the following factors: (1) position of the head of the pancreas in relationship to the long axis of the spine; (2) the level of the papilla of Vater; (3) 'filling defects' due to arterial impressions and arterial calcification; (4) pancreatic duct calibre; (5) the presence of branch, ductular dilatations, and cysts; ${ }^{1}$ (6) loop formations on the main duct and the presence of an accessory duct; (7) the shape of the pancreas; (8) length of the pancreatic duct.

Of the 120 cases successfully examined (table I), there were slightly more males than females $(61: 59)$, with increasing numbers in the later decades so that there were 43 studies in patients of 80 years and over. All cases with tumours of the pancreas were excluded from this analysis, apart from those enumerated in table IV pertaining to filling defects.

${ }^{1}$ Refers to first order branches (rami) and ductules to second order and beyond (canaliculi). 


\section{Results}

1 POSITION OF THE HEAD OF THE PANCREAS (TABLE II)

There were $49 \%$ of cases where the head of the pancreas was wholly to the right of the spine and $46 \%$ lying over the spine. In $5 \%$ the head of the pancreas was wholly to the left of the spine; this was in no way related to age (table III).
3 'FILling DEFECTS' DUE TO ARTERIAL IMPRESSIONS AND ARTERIAL CALCIFICATIONS (TABLE IV)

Linear defects due to the superior mesenteric artery $(32 \%$, fig $3 \mathrm{~d})$ or splenic artery $(7 \%)$ were present on 46 occasions with calcification in the superior mesenteric artery present less frequently than in the splenic $(15: 41)$. There was no correlation between filling defects and age, but the incidence of splenic

\begin{tabular}{|c|c|c|c|c|c|c|c|c|c|}
\hline \multicolumn{3}{|c|}{ Head of Pancreas Related to Spine } & \multicolumn{7}{|c|}{ Papilla of Vater at Body of } \\
\hline To Right & On & To Left & $L I$ & $L 2$ & $L 3$ & $L 4$ & $L 5$ & $S I$ & S2 \\
\hline 49 & 46 & 5 & 1 & 20 & 47 & 32 & 2 & 2 & 1 \\
\hline
\end{tabular}

Table II Position of head of pancreas and papilla of Vater ${ }^{1}$

${ }^{1}$ Results are expressed as percentages of total cases

2 LEVEL OF THE PAPILLA OF VATER

(TABLE II)

There were $21 \%$ of cases in which the level of the papilla of Vater was at L2 and above, and $79 \%$ of cases at the level of $\mathrm{L3}$ and below, with the vast majority (94\%) between the levels L2 and 4 . However, the papilla was found as low as the body of S2 (one case). The number of cases below the level of L3 was much commoner in the older age group, reaching a highly significant level $(P<0.01)$ (table III).

\begin{tabular}{|c|c|c|c|}
\hline & \multicolumn{2}{|l|}{ Age } & \multirow[t]{2}{*}{$x^{1}(1 d f)$} \\
\hline & -69 & $70-$ & \\
\hline $\begin{array}{l}\text { Head of pancreas on } \\
\text { or left of spine } \\
\text { Level of papilla below } L 3\end{array}$ & $\begin{array}{l}38 \% \\
16 \%\end{array}$ & $\begin{array}{l}54 \% \\
45 \%\end{array}$ & $\begin{array}{l}2.78 \\
9.23(P<0.01)\end{array}$ \\
\hline
\end{tabular}

Table III Position of head of pancreas and papilla of Vater related to age

\begin{tabular}{lll}
\hline & Filling Defect (\%) \\
\cline { 2 - 3 } & Arterial Impressions & Calcifications \\
\hline Superior mesenteric & & \\
artery & 32 & 15 \\
Splenic artery & 7 & 41 \\
Lymph nodes & 4 & \\
Metastases & 5 & \\
Carcinoma pancreas & 8 & \\
\hline
\end{tabular}

Table IV Filling defects

artery calcification was highly significant $(\mathrm{P}<0.01)$ and calcification in the mesenteric artery also reached a significant level $(\mathrm{P}<0.05)($ table $\mathrm{V})$.

4 PANCREATIC DUCT CALIBRE (FIG 1)

Duct widths (diameter) were measured on radiographs taken with the pancreas in situ (Kreel et al, 1973). The main duct was measured across the widest points in the head, body, and tail. The mean duct widths in $\mathrm{mm}$ for each decade over the age of 40 are shown in table VI and on a graph in figure 2. It can

\begin{tabular}{|c|c|c|c|c|c|}
\hline & \multicolumn{2}{|c|}{$\begin{array}{l}69 \text { Years of Age } \\
\text { Defect }(\%)\end{array}$} & \multicolumn{2}{|c|}{$\begin{array}{l}70 \text { Years of Age } \\
\text { Defect }(\%)\end{array}$} & \multirow[t]{2}{*}{$x^{2}(1 d f)$} \\
\hline & $\begin{array}{l}\text { Arterial } \\
\text { Impressions }\end{array}$ & Calcification & $\begin{array}{l}\text { Arterial } \\
\text { Impressions }\end{array}$ & Calcification & \\
\hline $\begin{array}{l}\text { Superior mesenteric } \\
\text { artery } \\
\text { Splenic artery } \\
\text { Other } \\
\text { Mesenteric artery }\end{array}$ & $\begin{array}{r}22 \\
3 \\
30 \\
-\end{array}$ & $\frac{22}{5}$ & $\begin{array}{l}36 \\
10 \\
28 \\
-\end{array}$ & $\begin{array}{l}\frac{49}{20} \\
\frac{-}{20}\end{array}$ & 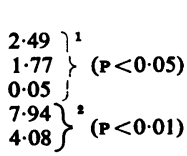 \\
\hline
\end{tabular}

Table V Filling defects due to arterial impressions and calcifications related to age

${ }^{1}$ Arterial impressions ${ }^{2}$ Calcifications 


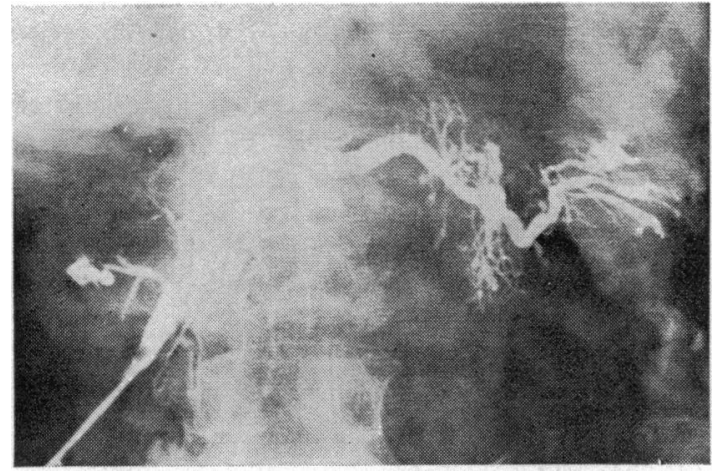

Fig 1 Necropsy retrograde pancreatography showing moderate dilatation with a calibre of $7 \mathrm{~mm}$ in a patient aged 71 years.

be seen that not only is the width of the duct related to age but increases at the rate of $8 \%$ per decade.

\begin{tabular}{llll}
\hline Age & Head & Body & Tail \\
\hline-49 & 3.2 & 2.4 & 1.4 \\
$50-$ & 4.3 & 3.5 & 1.8 \\
$60-$ & 5.0 & 3.5 & 2.0 \\
$70-$ & 4.6 & 3.5 & 2.1 \\
$80-$ & 5.3 & 4.0 & 2.1 \\
$\%$ increase per & 0.8 & 0.8 & 0.8 \\
year & 0.8 & & \\
\hline
\end{tabular}

Table VI Mean duct widths (logarithmic) in $\mathrm{mm}$

\section{THE PRESENCE OF DUCT DILATATIONS}

\section{AND CYSTS}

Canalicular dilatations, as manifested by the finding of peripheral rounded collections of barium, were common (table VII). If the individual spot of barium

\begin{tabular}{|c|c|c|c|c|c|c|c|}
\hline Normal peripheral & & $\cdots$ & $\cdots$ & $\cdots$ & $\cdots$ & $\cdots$ & $44 \%$ \\
\hline Branch dilatation . & . & $\cdots$ & . & $\cdots$ & $\cdots$ & $\cdots$ & $16 \%$ \\
\hline Ductule dilatation . & & $\cdots$ & $\cdots$ & . & . & . & .. $40 \%$ \\
\hline Branch + ductular & & . & . & . & . & . & $\ldots 10$ \\
\hline Large cysts . . & . & . & . & . & . & . & . \\
\hline Loop on duct & . & . & . & . & . & . & .. $18 \%$ \\
\hline
\end{tabular}

\section{Table VII Duct patterns}

was less than $2 \mathrm{~mm}$ it was designated a 'bobble', if there was conglomeration in an area, a 'sialectasis pattern', and if greater than $2 \mathrm{~mm}$, as a cyst (fig 3). It was found that the presence of cysts in the head of the pancreas reached a highly significant level $(P<0.01)$ and the branch and ductular dilatations in the tail were also significant $(P<0.05)$, although all these patterns were common in the elderly (tables VIII and IX).

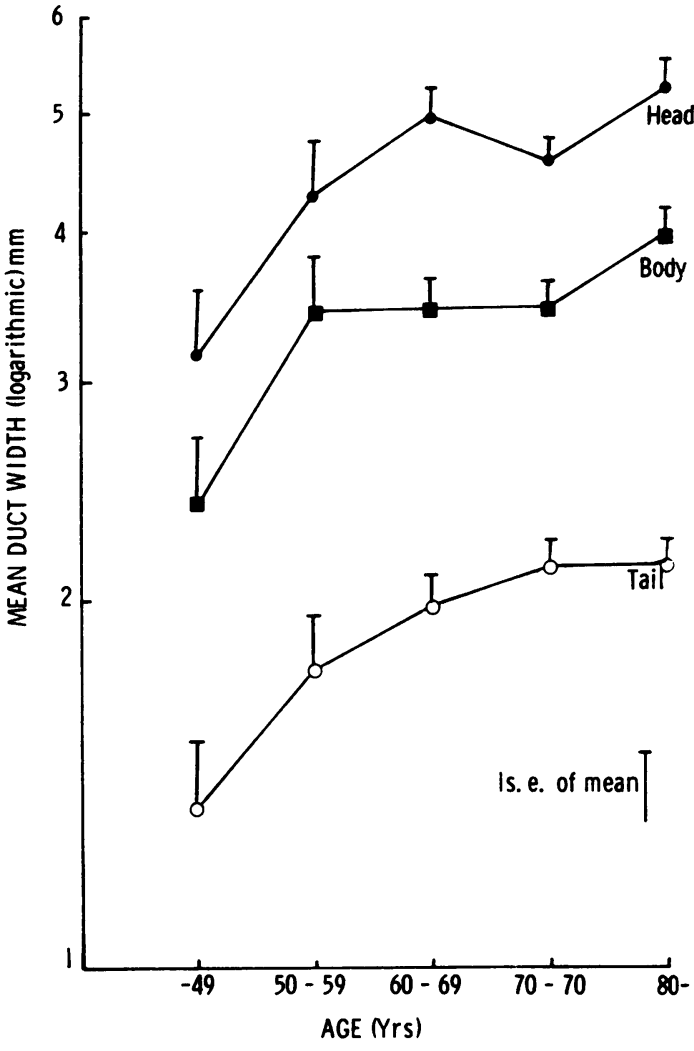

Fig 2 Duct widths in the head, body, and tail of the pancreas showing an increase in mean calibre in each area with age. The increase is proportionally the same for head, body, and tail.

\begin{tabular}{|c|c|c|c|}
\hline Age & Bobbles & Cysts & $\begin{array}{l}\text { Ductular } \\
\text { Dilatations }\end{array}$ \\
\hline $\begin{array}{l}-59 \\
60-69 \\
70-79 \\
80-\end{array}$ & $\begin{array}{l}23 \\
43 \\
46 \\
49\end{array}$ & $\begin{array}{l}15 \\
33 \\
44 \\
53\end{array}$ & $\begin{array}{l}23 \\
43 \\
44 \\
42\end{array}$ \\
\hline$x_{1}{ }^{2}$ & $2 \cdot 14$ & 0.81 & $6.66^{1}$ \\
\hline
\end{tabular}

Table VIII Percentage of cases with bobbles, cysts and ductular dilatations in the head of the pancreas related to age

${ }^{1} \mathrm{P}<0.01$

\begin{tabular}{llll}
\hline & \multicolumn{1}{l}{ Age } & & $x^{2}(1 d f)$ \\
\cline { 2 - 3 } & -69 & $70-$ & \\
\hline Head & $27 \%$ & $36 \%$ & $0 \cdot 88$ \\
Body & $49 \%$ & $43 \%$ & 0.35 \\
Tail & $30 \%$ & $52 \%$ & $5 \cdot 32^{1}$ \\
\hline
\end{tabular}

Table IX Sialectasis pattern

${ }^{1} \mathrm{P}<\mathbf{0 . 0 5}$ 


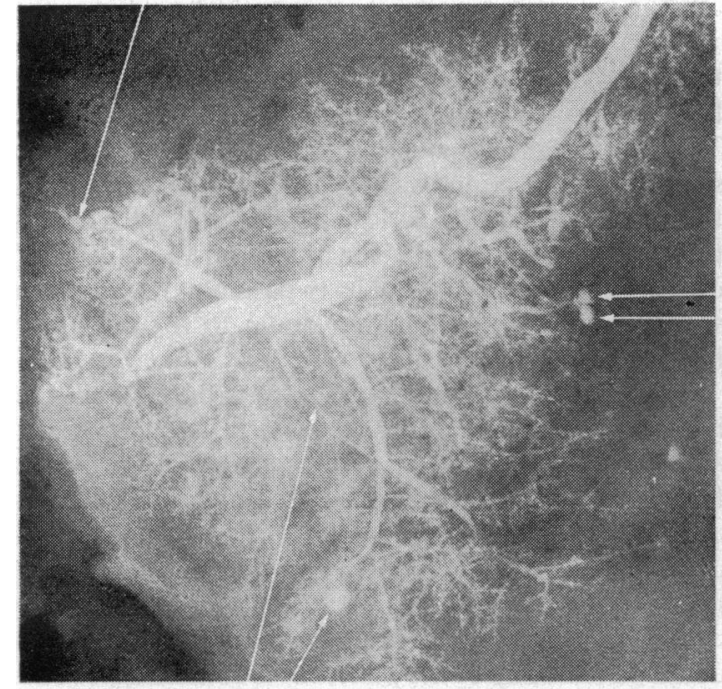

Fig $3 a$

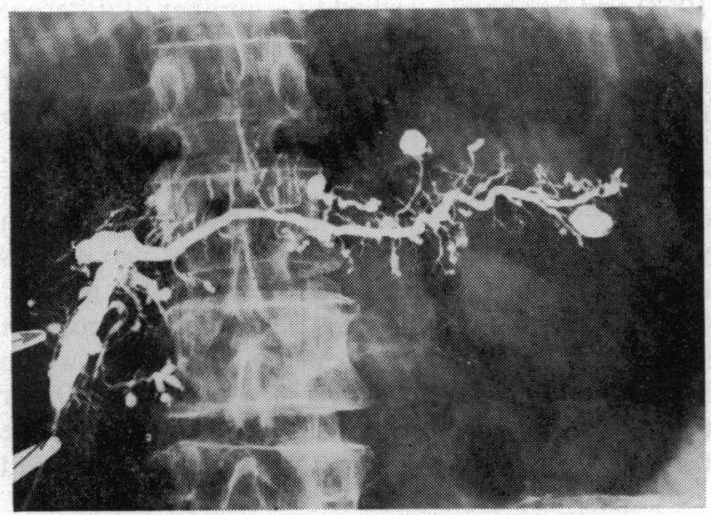

Fig $3 c$

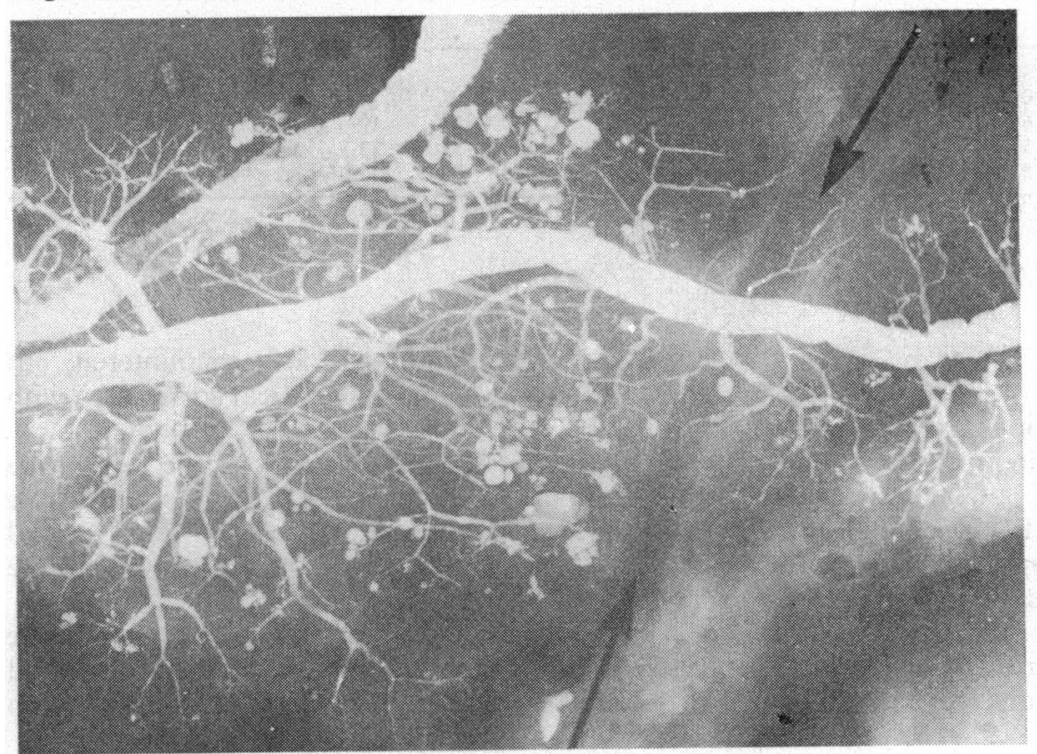

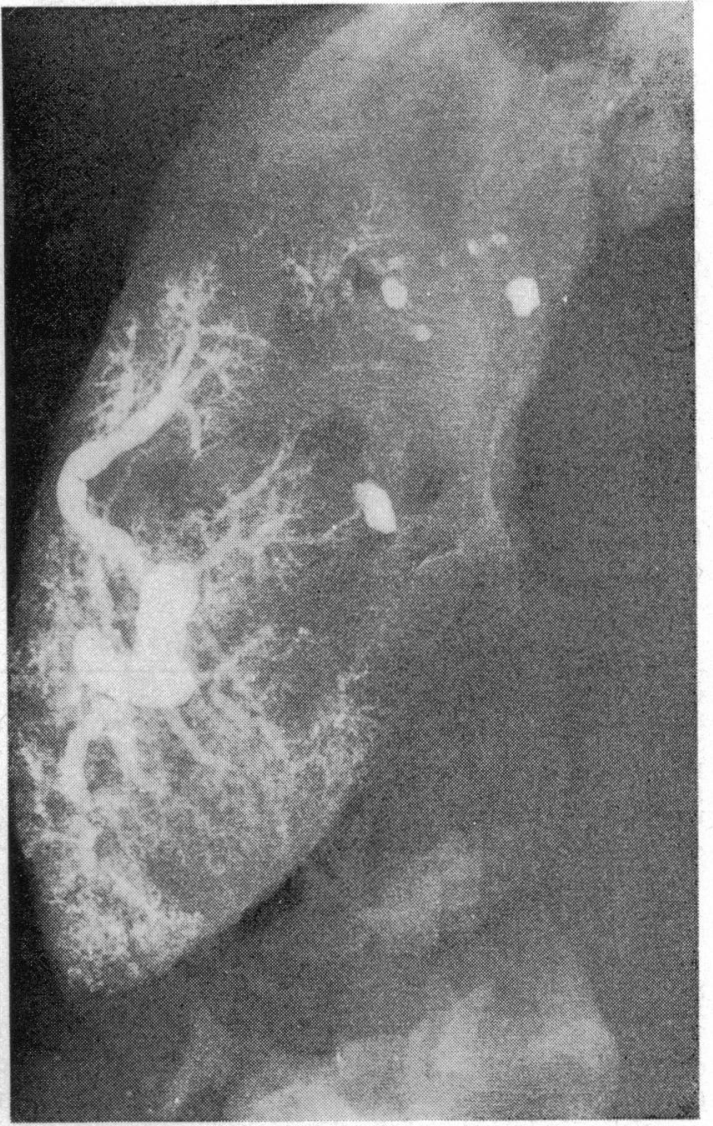

Fig $3 b$
Fig 3 a Normal fine duct pattern (slightly enlarged), apart from about 10 'bobbles', ie, small round collections of barium at the periphery, most of which measure less than $2 \mathrm{~mm}$.

b Cross section showing dilatation of major branches and also peripheral 'cysts', ie, rounded collections of barium greater than $2 \mathrm{~mm}$ in diameter. c Multiple cystic spaces in the head, body, and tail, one of which is up to $1 \mathrm{~cm}$ in diameter.

d Multiple dilatations producing a 'sialectasis' orracemose pattern. The arrows indicate the site of the superior mesenteric linear filling defect pattern. 
6 LOOP FORMATIONS ON THE MAIN PANCREATIC DUCT AND ACCESSORY DUCT A loop on the main duct was found in $18 \%$ and an accessory duct in $28 \%$, with a completely separate opening from that of the common bile duct in $6 \%$ of cases. A double duct in the tail of the pancreas was found in one instance. The incidence of all these factors was found to be independent of age.

\section{THE SHAPE OF THE PANCREAS}

The pancreas has a variable shape, being oblique, horizontal, sigmoid, L, inverted $\mathrm{U}$, and inverted $\mathrm{V}$. The incidence of each of these shapes is given in table X. Again, there was no particular relationship of shape to age.

\begin{tabular}{|c|c|c|c|c|c|c|c|c|c|}
\hline Oblique & . & $\cdots$ & $\ldots$ & $\cdots$ & $\ldots$ & $\ldots$ & $\cdots$ & $\cdots$ & $37 \%$ \\
\hline Sigmoid & . & . & . & .. & $\ldots$ & .. & .. & . & $27 \%$ \\
\hline Transverse & . & . & .. & . & . & .. & $\ldots$ & . & $2 \%$ \\
\hline Horseshoe & . & . & .. & . & . & .. & . & $\ldots$ & $7 \%$ \\
\hline L-shaped & . & . & . & . & . & .. & . & . & $27 \%$ \\
\hline Inverted-V & . & . & .. & . & . & . & . & . & $1 \%$ \\
\hline
\end{tabular}

Table X Shape of pancreas

\section{THE LENGTH OF THE PANCREATIC DUCT}

The length of the pancreatic duct was measured both in situ and on the radiograph after removal of the pancreas, and there was no significant difference with age either in lengths of the duct in situ, in true lengths on the separate specimen, or in the difference between these measurements (table XI). that the pancreas moves pari passu with the duodenal loop, as shown by the position of the papilla of Vater. This fact must be taken into account in isotope scanning of the pancreas in the elderly, as the head of the pancreas may be as low as the body of S2, and this would also account for the 'non-visualization' of the pancreas in some elderly patients, because the scan was not in fact carried down to a sufficiently low level.

The head of the pancreas may be entirely to the left of the spine in some cases, and this fact must also be borne in mind in interpreting isotope scans. However, this is not an age-related phenomenon but does stress the importance of correlation of duodenography with isotope scanning as has been previously recommended (McCarthy et al, 1969).

It has been recognized for some time that a filling defect in the body of the pancreas is commonly found on isotope scanning (Melmed, Agnew, and Bouchier, 1968) and has been ascribed to a number of different factors, including pressure from the spine.The present study has, however, clearly shown a vertical linear filling defect in the body of the pancreas due to 'pressure' from the superior mesenteric artery. This phenomenon is not age-related, with an incidence of about $39 \%$, although arterial calcification was significantly commoner in the older age groups (figs $4 a$ and b). It is of some interest that calcification is much commoner in the splenic artery and that senile or degenerative aneurysms are also often found in the splenic artery (Kreel, 1972). Other filling defects, such as those due to osteophyte formation, aortic compression, metastases, and

\begin{tabular}{|c|c|c|c|c|}
\hline$A g e^{1}$ & Number & In situ & Specimen & Difference \\
\hline $\begin{array}{l}30- \\
50- \\
60- \\
70- \\
80-\end{array}$ & $\begin{array}{r}5 \\
8 \\
21 \\
33 \\
29\end{array}$ & $\begin{array}{l}170.4 \pm 13.8 \\
190.4 \pm 10.9 \\
196.4 \pm 6.7 \\
198.4 \pm 5.4 \\
194.3 \pm 5.7\end{array}$ & $\begin{array}{l}191.0 \pm 12.5 \\
209.5 \pm 9.9 \\
215.4 \pm 6.1 \\
211.6 \pm 4.9 \\
207.9 \pm 5.2\end{array}$ & $\begin{array}{l}20.6 \pm 7.7 \\
19.1 \pm 6.1 \\
19.0 \pm 3.7 \\
13.3 \pm 3.0 \\
13.6 \pm 3.2\end{array}$ \\
\hline
\end{tabular}

Table XI Mean length of duct

The age differences are not significant at $P=0.05$

\section{Discussion}

The mobility of the duodenal loop in a cranio-caudal direction was commented upon in an earlier work in relation to isotope scanning of the pancreas (McCarthy, Kreel, Agnew, and Bouchier, 1969) and in particular to older age groups. It was thought, however, that there might be a disassociation between the duodenal loop and the head of the pancreas, the loop being displaced downwards more than the pancreas. From the present study it is quite clear enlarged lymph nodes, were also encountered, but were too few to attempt a statistical correlation with age.

In recent publications on endoscopic retrograde cholangiopancreatography (ERCP), considerable emphasis is placed on the duct calibre being normal (Cotton, 1972; Ogoshi, Kiwa, and Hara, 1973) in the diagnosis of pancreatic lesions.

The upper limit of normal for duct calibre in the head of the pancreas is usually given as $6 \mathrm{~mm}$, and Millbourn (1960) mentioned diameters up to $11 \mathrm{~mm}$ 


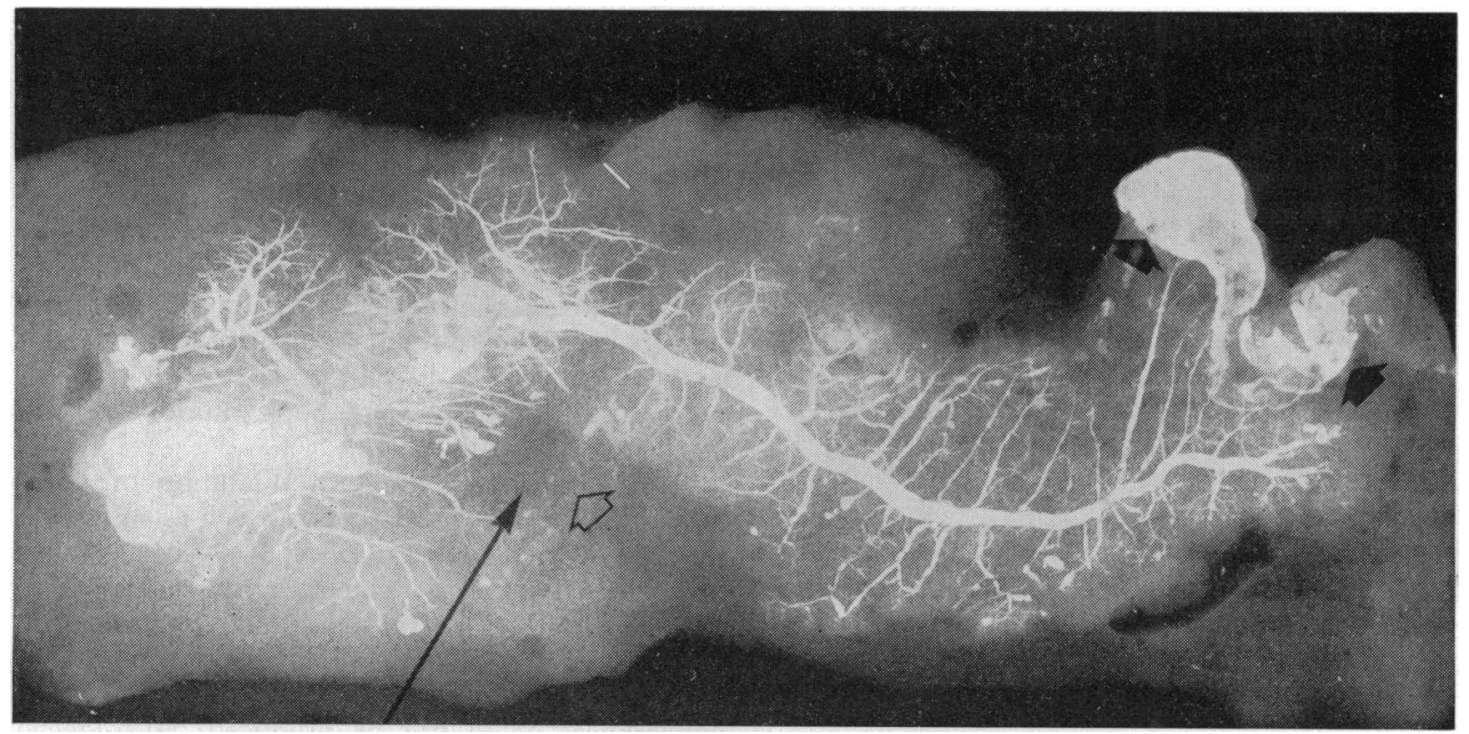

Fig 4a Slight calcification in the superior mesenteric artery (arrow head). The arrow points to the adjacent linear pancreatic filling defect. Marked calcification in the splenic artery with a small calcified aneurysm.

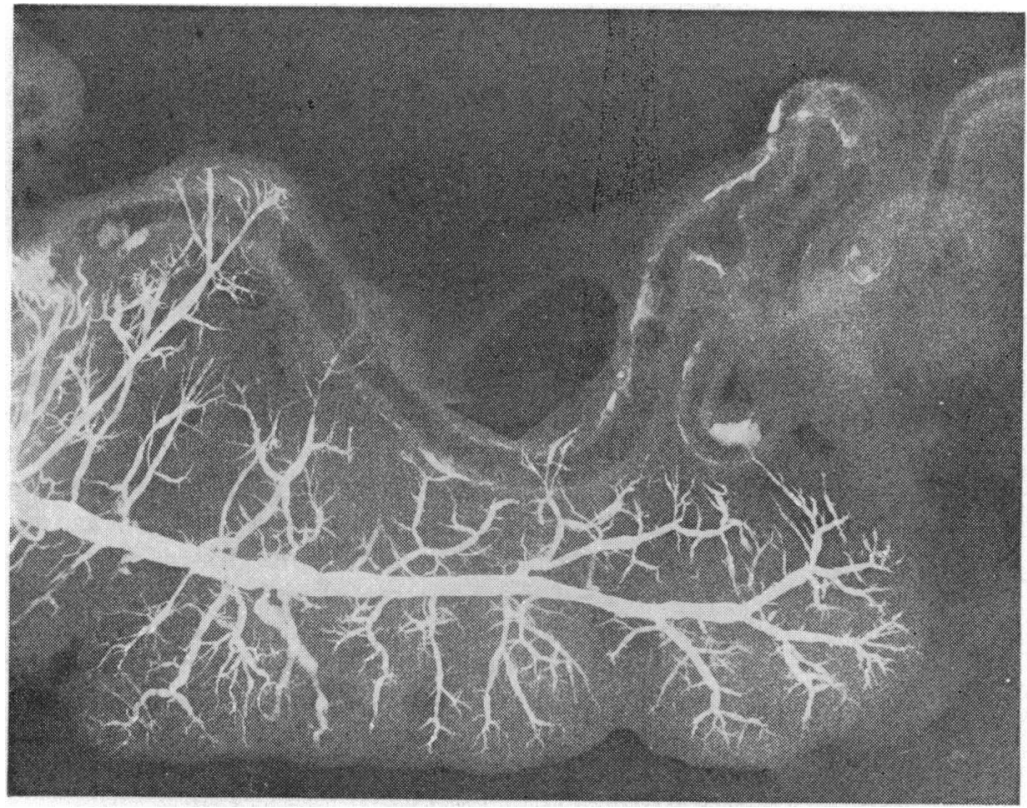

Fig $4 \mathrm{~b}$ Compressed pancreatic tissue caused by a calcified tortuous splenic artery.

at necropsy studies. There has, however, been no attempt to correlate duct calibre with age of subjects. In the present study, measurements of duct width correspond closely with those given in the literature in younger age groups but there is marked divergence in the group over 70 years of age. Furthermore it can be seen that there is, in fact, a steady increase in duct calibre with age throughout the whole of the pancreas - head, body, and tail - and that proportionally this increase is the same for these areas. As has been mentioned previously and shown in table VI, this increase is at the rate of $0.8 \%$ per year.

Ducts dilate also with obstruction, particularly from primary pancreatic carcinoma and in chronic 


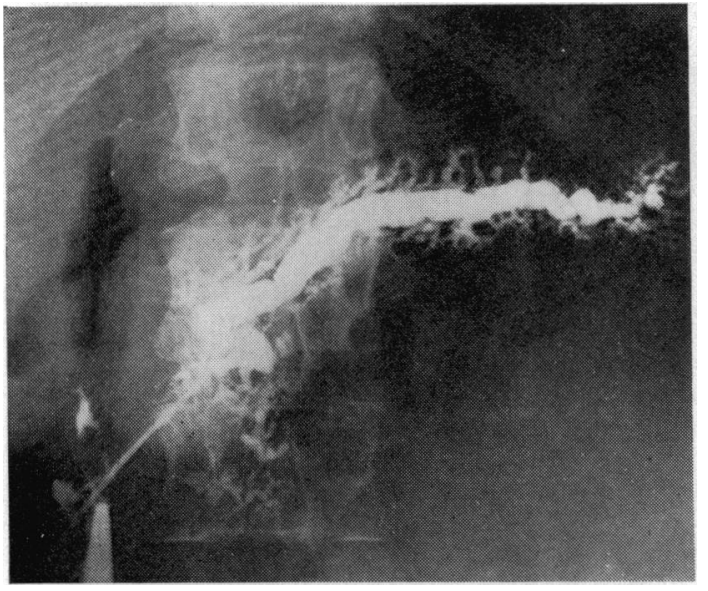

Fig 5 Dilated pancreatic duct due to obstruction from a carcinoma in the head of the pancreas.

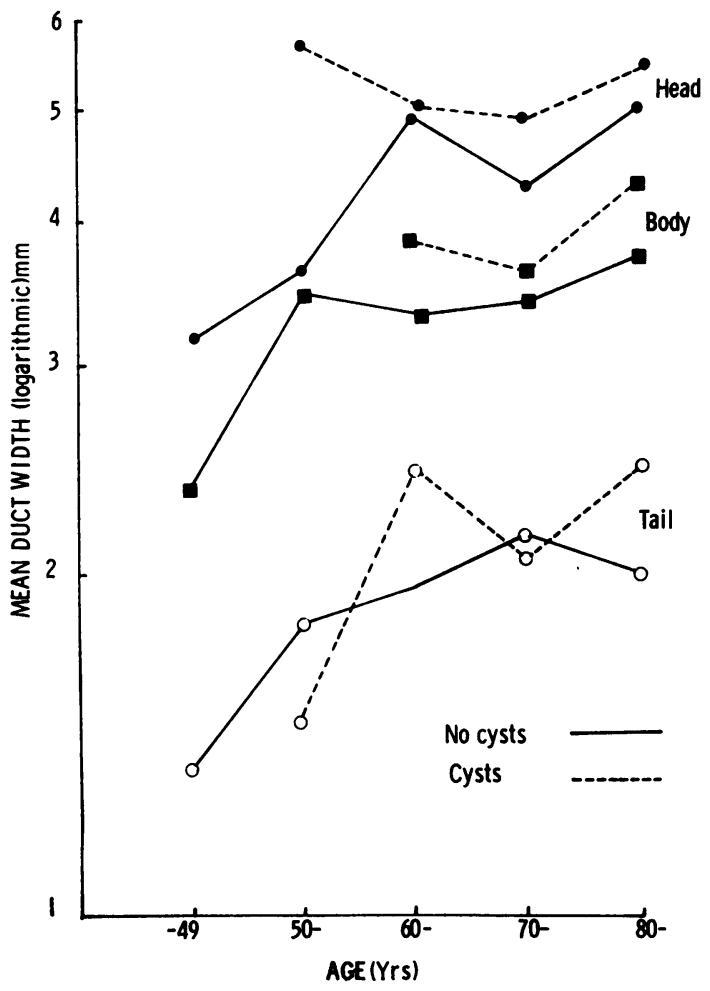

Fig 6 Graph to show that the mean duct width is higher in cases with cyst formation. pancreatitis. Whereas the normal dilated duct in the elderly retains its uniform tapering appearance with smooth margins, this is not so in obstruction or chronic pancreatitis. In the latter conditions, marginal indentations are present or, as in chronic pancreatitis, intervening strictures produce the "chain of lakes' appearances. There is also, in obstructive pancreatopathy, general dilatation of side branches (fig 5), and with senile duct dilatation there are only scattered and intermittent branch dilatations associated with ductular dilatations.

On histology there were both interlobular and intralobular duct dilatations.

These common findings of dilatation of interlobular and intralobular ducts, as well as small cyst formations in the elderly, were unexpected. As has been shown, there is a significant correlation with age (tables VII and VIII). To rule out any artefacts, pancreas injections in dogs were carried out at varying times after death up to 72 hours and similar appearances could not be produced. Histological examination showed intact lobular structure and ducts in the cases with ductular dilatations. The whole phenomenon is being examined in much greater detail at present and will be the subject of a further communication.

It can, however, be mentioned at this stage that there is no associated evidence of pancreatic fibrosis, round cell infiltration, or obvious arterial lesions. Another point to be made with regard to this phenomenon of ductular dilatation is that there is a significant correlation with widening of the main duct in old age (fig 6) so that cyst formation is more common in association with ducts of greater width (table XII).

Long narrowing of the main duct was found in two instances. In one, this was in the area across the spine, but in the other case no explanation could be found. Again, the finding of duct narrowing is being stressed in the clinical context (Kato and Nakazowa, 1973) and inferences are being drawn as to the presence of intrapancreatic infiltrating lesions. It would appear that if this is the only sign great care must be taken not to be dogmatic about making the diagnosis of carcinoma.

\begin{tabular}{lll}
\hline & No Cysts & Cysts \\
\hline-49 & $3 \cdot 2$ & - \\
$50-$ & $3 \cdot 7$ & $5 \cdot 7$ \\
$60-$ & $4 \cdot 9$ & $5 \cdot 0$ \\
$70-$ & $4 \cdot 3$ & 4.9 \\
$80-$ & $5 \cdot 0$ & 5.4 \\
\hline
\end{tabular}

Table XII Mean duct widths in the head of the pancreas in relation to the presence of cysts (logarithmic) in $\mathrm{mm}^{1}$ Mean log ratio $+0.5 \pm 0.03$ 


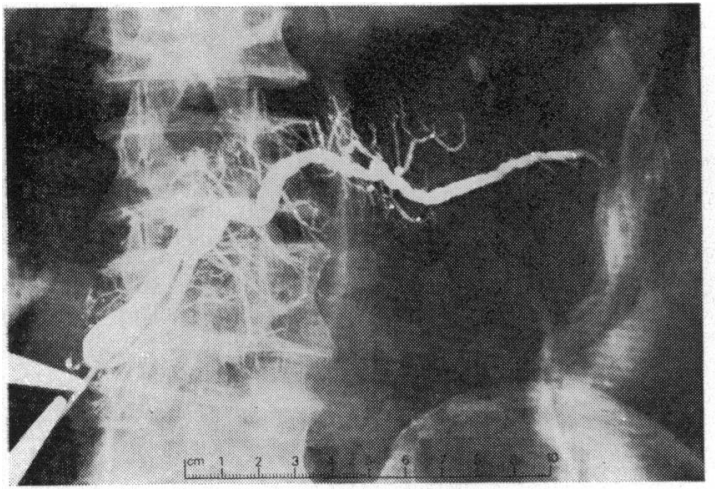

Fig 7 (a and b) Duct lengths in situ compared with specimen duct length. In this case, the specimen duct length is approximately $80 \mathrm{~mm}$ greater.

Fig 7a

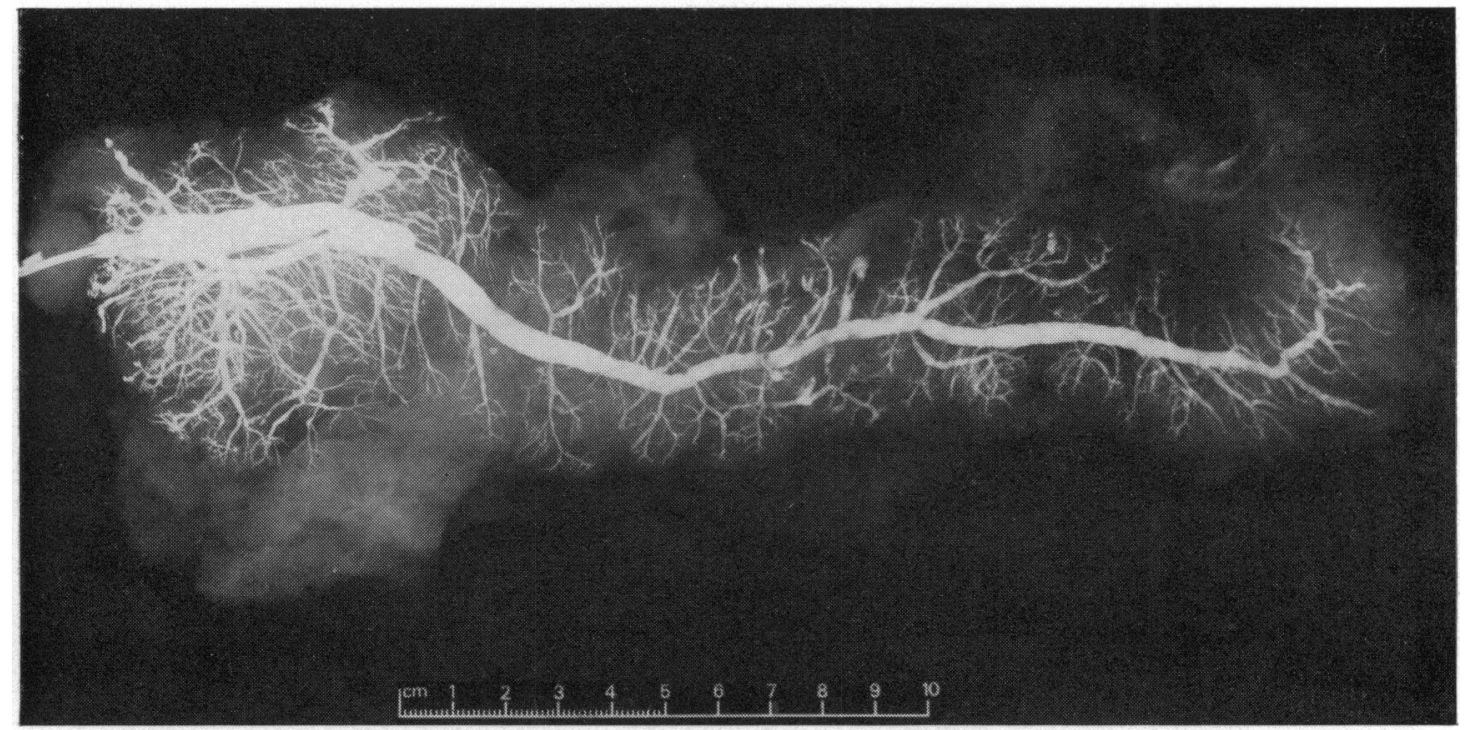

Fig $7 b$

True duct lengths, as measured on the specimens, varied from $97 \mathrm{~mm}$ to $317 \mathrm{~mm}$; in the vast majority of cases the specimen length was greater than the length in situ (table XI, fig 7), and the maximum difference was $104 \mathrm{~mm}$. However, in nine instances the duct on the specimen was, in fact, shorter than the length in situ. After repeatedly reviewing the radiographs, no explanation for this could be found. There was no correlation between mean duct length and age or in the difference between the duct length in situ and in the specimen and age.

With regard to the other anatomical variations of the pancreas, including a double duct in the tail, the presence of an accessory duct, loop on the duct, and the various shapes, no correlation with age could be demonstrated. Nonetheless, these variations are of considerable importance in interpreting radiological and isotope scanning appearances and must be constantly borne in mind.

\section{Conclusion}

This study shows that definite changes occur in the pancreas with increasing age. These changes must be taken into account in assessing duct pancreaticograms if false interpretations are to be avoided.

Our thanks are due to Richard Bowlby of the Department of Medical Illustration, Clinical Research Centre, Northwick Park Hospital, for photographs and prints, to Mr Michael Healy, Head of the Division of Computing and Statistics, for the analysis and tabulation of the data in this paper, and also to Mrs P. McKillop for the secretarial work involved in the preparation of the manuscript. 


\section{References}

Cotton, P. B. (1972). Cannulation of the papilla of Vater by endoscopy and retrograde cholangiopancreatography (ERCP). Gut, 13, 1014-1025.

Kato, K., and Nakazawa, S. (1973). A basic study in the visualisation of the pancreatic and biliary ducts-anatomy and opacified pictures of the ducts of the pancreas and biliary tract. Stomach and Intestine-Japanese Journal, 8, 342-343.

Kreel, L. (1972). The recognition and incidence of splenic artery aneurysms: a historical review. Austr. Radiol., 16, 126-136.

Kreel, L., Sandin, B., and Slavin, G. (1973). Pancreatic morphology: a combined radiological and pathological study. Clin. Radiol., 24, 154-161.
McCarthy, D. M., Kreel, L., Agnew, J. E., and Bouchier, I. A. D. (1969). Value of hypotonic duodenography as an adjunct to pancreatic scanning. Gut, 10, 665-673.

Melmed, R. N., Agnew, J. E., and Bouchier, I. A. D. (1968). The normal and abnormal pancreatic scan. Quart. J. Med., 37, 607624.

Millbourn, E. (1960). Calibre and appearance of the pancreatic ducts and relevant clinical problems. Acta chir. scand., 118, 286-303.

Ogoshi, K., Kiwa, M., and Hara, Y. (1973). Retrograde pancreatography with emphasis on carcinoma. Stomach and Intestine (I To Cho), 8, 300-301.

Sandin, B., Kreel, L., and Slavin, G. (1973). The pancreas: radiographic demonstration of pancreatic morphology at autopsy. Radiography, 39, 151-157. 